\title{
BEHAVIORAL INDICATORS IN MARINE CONSERVATION: LESSONS FROM A PRISTINE SEAGRASS ECOSYSTEM
}

\author{
Michael R. Heithaus, ${ }^{a, *, \dagger}$ Aaron J. Wirsing, ${ }^{a, \dagger}$ Alejandro Frid, ${ }^{b}$ \\ AND LAWRENCE M. DiLL ${ }^{\mathrm{c}}$ \\ ${ }^{a}$ Department of Biological Sciences, Florida International University, $3000 \mathrm{NE} \mathrm{151st,}$ \\ North Miami, Florida 33181, USA \\ ${ }^{b}$ Department of Biology, Dalhousie University, Halifax, Nova Scotia B3H 4J1, Canada \\ 'Department of Biological Sciences, Simon Fraser University, 8888 University Dr., \\ Burnaby, British Columbia V5A 1S6, Canada
}

\begin{abstract}
In light of ongoing changes to marine ecosystems, there is a need for behavioral indicators that can identify critical habitats and assess anthropogenic impacts. Although the application of behavior to conservation has yielded mixed results, habitat selection behavior has promise as such an indicator. Terrestrial studies and a decade of work in Shark Bay's pristine seagrass ecosystem show that habitat selection theory based on the ideal free distribution can be used to assess critical habitats based on food and safety and signal impacts of anthropogenic disturbance. One lesson from our studies of dugongs (Dugong dugon) and other species at risk from tiger sharks (Galeocerdo cuvier) is that physical attributes of habitats may influence the effects of predators, and, by extension, human disturbance. These species generally prefer seagrass bank edges, which facilitate escape from sharks, even though shark density is lower over interior portions of the banks. Thus, habitat selection indicates that a bank's quality is determined largely by its proportion of edge microhabitat rather than its size, and that the presence of predators in neighboring habitats can influence prey space-use decisions where predators are scarce or absent. By extension, efforts to curb the effects of human disturbance, which can mimic those of predation risk, may be unsuccessful if protected areas border those subject to continued disturbance. Future marine studies should assess habitat selection in more disturbed habitats and across a range of physical settings to better elucidate the conservation benefits of using habitat selection as a behavioral indicator.
\end{abstract}

\section{INTRODUCTION}

Marine habitats have been, and continue to be, degraded by human activities (Jackson et al., 2001; Lotze et al., 2006; Orth et al., 2006; Halpern et al., 2007; Myers et al., 2007). Marine conservation, however, lags behind that for terrestrial and freshwater systems in

\footnotetext{
*Author to whom correspondence should be addressed. E-mail: heithaus@ fiu.edu

These authors contributed equally to this work.

Received 11 August 2007, accepted 18 November 2007.
} 
part because of logistical obstacles, the high mobility of many marine species, and a lack of funding (Reynolds and Jennings, 2000; Norse and Crowder, 2005). Thus far, marine conservation has focused primarily on the most obvious threats like pollution, habitat modification and destruction, and overfishing. In general, the importance of understanding behavior and the possibility that the behavior of marine organisms might inform conservation decisions have been largely overlooked (but see Reynolds and Jennings, 2000; Dill et al., 2003; Parrish, 2005).

In spite of some controversy (Caro, 2007), the use of behavioral indicators to inform conservation and management decisions for terrestrial systems has begun to gain acceptance (Buchholz, 2007). Some types of behavior may signal the level of threat to species of concern (Caro, 2005) and help identify important habitats at the appropriate spatial scale for their conservation (e.g., Gill et al., 1996; Sutherland, 1998; Morris 2003a). For example, African mammals that are hunted are more wary than those that are not. Thus, wariness (e.g., vigilance) might indicate hunting or poaching levels that have been otherwise undocumented (Caro, 2005). Habitat selection behavior also is of great interest for conservation programs (e.g., Morris, 2003a), both because it influences multi-species interactions and because it can be used to identify distinct habitats and their functional effect on fitness from the perspective of the organism (Knight and Morris, 1996; Morris, 2003b). If management strategies lump together habitats that animals view as distinct, erroneous assumptions about the processes that influence population and community dynamics likely will follow. Thus, habitat selection patterns and habitat shifts in response to environmental variation could reliably indicate the number and types of habitats in a landscape (Knight and Morris, 1996; Morris, 2003a).

Habitat selection behavior is likely to be a useful indicator for conservation efforts in marine systems for two primary reasons. First, coastal habitats are undergoing rapid destruction and modification (e.g., Orth et al., 2006). Thus, it is important to determine the quality of different habitats from the perspective of marine species in order to predict the outcomes of anthropogenic changes and to reverse the process of degradation. Second, ecotourism (e.g., vessel-based tourism, recreational diving) is increasingly "sold" as a non-consumptive commodity that might encourage the conservation of marine habitats and species. Human disturbance, however, is analogous to predation risk in that it can cause habitat shifts and other behavioral responses that compromise access to food, mates, or other resources that influence fitness (Frid and Dill, 2002; Gilroy and Sutherland, 2007). Thus, in spite of good intentions for non-consumptive use of natural resources, ecotourism could harm the very marine species it intends to protect (e.g., Bejder et al., 2006; Williams et al., 2006), and habitat selection behavior could be a metric for these effects. For example, Bejder et al. (2006) monitored bottlenose dolphin (Tursiops aduncus) habitat use within an area disturbed by boats and an adjacent, less disturbed area during a period of increasing vessel-based ecotourism. Dolphin abundance decreased $15 \%$ inside the disturbed area but did not change in the control area. Individuals shifting from the disturbed site into less preferred and unfamiliar areas likely experienced reduced energy acquisition rates and an increased risk of predation (Lusseau, 2004). 
Since 1997 , we have been studying the relatively pristine seagrass ecosystem of Shark Bay, Western Australia, as a model system for understanding the importance of behavioral decisions in structuring marine community dynamics. Much of our work to date has focused on the habitat selection behavior of several large vertebrates in response to spatial variation in food resources and temporal and spatial variation in risk from the top predator in the system, the tiger shark (Galeocerdo cuvier). Although conservation issues in Shark Bay are relatively minor at this time, our studies have implications for its continued protection and the conservation of other, more heavily impacted, systems.

In the remainder of this paper, we first review some of the theory that might help us define habitat quality. Next, we synthesize our ten years of research in Shark Bay in the context of developing behavioral indicators for habitat quality that may be of use to conservation and management. Our primary goals are to show (1) that habitat selection analyses analogous to those applied in terrestrial systems can be developed in marine environments and then applied to identify critical habitats and (2) that responses of large marine vertebrates to predation risk conform to theoretical predictions from behavioral ecological theory and, as a result, general principles can be used to generate testable predictions about the likely responses of marine taxa to human disturbance.

\section{BEHAVIORAL INDICATORS OF HABITAT QUALITY}

One of the most important tasks facing marine conservation biologists is to identify critical habitats for species of concern so that these habitats can be protected. While protecting food resources or breeding habitats has been the focus of conservation in marine habitats, most species are also at risk of predation. Thus, effective designation of critical habitats will often require that measures of resource availability be integrated with information on habitat safety.

An ever-growing literature indicates that the overall impact of predators, directly on their prey and indirectly on communities, operates through both consumptive (lethal) and non-consumptive (non-lethal) mechanisms. Interestingly, non-lethal impacts of predators, through changes in activity levels or shifts in habitat use by their prey, may be of equal or greater magnitude than lethal effects on prey populations and communities (e.g., Schmitz et al., 2000; Peacor and Werner, 2001; Preisser et al., 2005; Griffin and Thaler, 2006; Trussel et al., 2006). These non-lethal effects are not even across a landscape and cause animals to evaluate the value of a particular habitat based on profitability (e.g., food availability) and safety from predators ("landscape of fear", Laundré et al., 2001; Wirsing et al., 2008).

The greatest difficulty in using habitat selection under risk of predation as a behavioral indicator in marine systems is developing useful metrics. Habitat quality in terrestrial systems, which can be used to identify habitats that are most desirable from the perspective of both food and safety, can be measured using giving up densities (GUD; e.g., Brown and Kotler, 2004). The GUD approach is based on the premise that as the harvesting rate of resources declines, owing to depletion, foragers will cease foraging and seek other resources or a refuge at a higher remaining density of resources in danger- 
ous habitats rather than safe ones. In other words, foragers require greater "hazardous duty pay" when foraging in dangerous habitats. This framework works well for studies of rodents (e.g., Yunger et al., 2002; Kotler et al., 2004) and herbivores (e.g., Altendorf et al., 2001; Hochman and Kotler, 2007), and can aid in creating a view of the landscape that integrates the distribution of resources and the perceived safety of habitats. However, the GUD framework is much harder to apply to species foraging on mobile prey, as many marine species of conservation concern do, or those that feed in large expanses of seagrass that are not depleted (harvesting rates do not decline), such as sirenians and sea turtles. Thus, a different theoretical framework is needed for the majority of marine settings.

Ideal free distribution (IFD) theory (Fretwell and Lucas, 1969) represents one such alternative framework. IFD-based theory assumes that individuals will be distributed across habitats such that, at equilibrium, individual fitness is equal in all habitats. In a pure foraging context, this would suggest that the proportion of individuals in a habitat would be equal to the proportion of food available in that habitat. There are many reasons to expect deviations from IFD, including imperfect knowledge of resource distribution, unequal competition among individuals, and predation risk (see Tregenza, 1995). Nonetheless, measurement of deviations from the null expectations of IFD is a means to assess habitat quality and detect responses to changes in the environment (van Baalen and Sabelis, 1993). Importantly, the IFD predicts that spatial shifts in food availability will result in habitat shifts. Thus, its application requires that densities of animals in habitats of interest be corrected for food supply across habitats.

Similar information can be gained using habitat isodars, which are graphs of the density of individuals in one habitat versus that in another when expected fitness is equivalent in both (e.g., Morris, 2003a). The calculation of isodars, however, requires simultaneous assessment of animal densities in adjacent patches across a range of overall population densities, which is logistically difficult for many marine species.

\section{THE SHARK BAY STUDIES}

While top-down effects, including non-lethal ones, have been widely accepted in terrestrial systems and even considered in a conservation framework (e.g., Ripple et al., 2001; Ripple and Beschta, 2003), non-lethal effects have been almost completely ignored in the marine realm (Wirsing et al., 2008). Our studies in Shark Bay suggest, however, that non-lethal effects of tiger sharks on their prey are likely substantial and that the theoretical framework of the predation risk effects is applicable across taxa and systems. In other words, we have been able to use this framework to make general predictions about the dynamics of the Shark Bay system, integrating measures of habitat profitability (resources) and safety from predators (Wirsing et al., 2008).

Shark Bay is a large $\left(13,000 \mathrm{~km}^{2}\right)$ semi-enclosed bay along the central coast of Western Australia $\left(25^{\circ} 45^{\prime} \mathrm{S}, 113^{\circ} 44^{\prime} \mathrm{E}\right)$ that is divided into Eastern and Western Gulfs by barrier islands and peninsulas (see Heithaus, 2001). Seagrasses cover approximately $4000 \mathrm{~km}^{2}$ of the bay. Due to its remote nature and designation as a Marine Park and World Heritage 
Area in 1991, Shark Bay is subject to very low fishing pressure (Heithaus, 2001) and is probably one of the world's most pristine remaining seagrass ecosystems.

The community of large vertebrates in Shark Bay is diverse and composed of large populations that probably have not been reduced by human activities (e.g., Preen et al., 1997; Gales et al., 2004; Heithaus et al., 2005). The Bay's two large-bodied grazers, green sea turtles (Chelonia mydas) and dugongs, are subject to few anthropogenic impacts but are at risk of predation from a large population of tiger sharks (Heithaus, 2001). The tiger shark population of Shark Bay is not at risk from harvest along much of the Western Australian coast, and tiger shark catch rates in Shark Bay are substantially higher than in other areas of the world where tiger shark populations have been sampled systematically (compare Heithaus, 2001, and Wirsing et al., 2006, with Heithaus et al., 2007a; Papastamatiou et al., 2006).

Our ca. $150 \mathrm{~km}^{2}$ study area in the Eastern Gulf is patchy, with multiple shallow banks ( $\leq 4.5 \mathrm{~m}$ depth), largely covered by seagrass, and surrounding deeper waters (generally 6-12 m depth) with primarily sandy bottoms. Shallow banks can be divided into interior ( $<2.5 \mathrm{~m}$ depth and $>75 \mathrm{~m}$ from water $>4.5 \mathrm{~m}$ depth) and edge (waters $2.5-4.5 \mathrm{~m}$ depth and waters $<2.5 \mathrm{~m}$ depth within $75 \mathrm{~m}$ of water $>4.5 \mathrm{~m}$ depth) microhabitats, while deep habitats can be subdivided into open water microhabitats, with relatively low current velocities, and channel microhabitats with swift currents. We have assessed habitat selection by focal species that are prey to tiger sharks by conducting more than 2,500 passes through transects that are replicated across all major microhabitats (see Heithaus and Dill, 2002, 2006; Wirsing et al., 2007a,b).

There is considerable temporal variation in the abundance of tiger sharks in the study area, with relatively rapid transitions between seasons with high shark catch rates and very low shark catch rates (Heithaus, 2001; Wirsing et al., 2006). Shark abundance is consistently high from September-May, but sharks may either be present in substantial numbers, or largely absent, from June-August, depending on the year (Heithaus, 2001; Wirsing et al., 2006). Therefore, we are able to analyze patterns of habitat and microhabitat use by potential prey species relative to shark abundance in either a continuous or discrete ("present" or "absent") manner without the confound of seasonal variation in other factors, such as temperature (see Heithaus and Dill, 2002, 2006; Wirsing et al., 2007a). By studying multiple species simultaneously, we have endeavored to (1) determine the ecological role of tiger sharks as apex predators and (2) understand the factors influencing habitat and microhabitat use by each species that is at risk from tiger sharks.

We have used an IFD framework in Shark Bay to determine how temporal variation in predation risk influences habitat use by tiger shark prey species. For both grazers (dugong) and piscivores (dolphins, Tursiops aduncus; pied cormorants, Phalacrocorax varius), we have assumed that individuals should be spread across habitats and microhabiats proportional to the distribution of their food. Thus, we can calculate the relative density of individuals in a habitat as the density of animals in the habitat divided by the proportion of food available there. Under an IFD, relative densities in each habitat or microhabitat should be the same as long as fitness declines with increasing consumer density. We can then calculate the "hazardous duty pay" required to use dangerous habitats, 
and identify relatively safe and relatively dangerous habitats through deviations from relative densities observed when sharks are not present. Relative densities will be higher in safer habitats because individuals will sacrifice foraging opportunities for safety, and they will be lower in dangerous habitats where hazardous duty pay is required.

Our studies in Shark Bay illustrate the utility of this approach. During periods of low shark density, dolphins, dugongs, and cormorants are found at similar relative densities in deep and shallow habitats. However, as shark abundance increases, all three of these species reduce their use of dangerous shallow habitats and are found in much higher relative densities in deep habitats (Heithaus and Dill, 2002; Heithaus, 2005; Wirsing et al., 2007b). At smaller spatial scales we have found that, counterintuitively, dolphins (Heithaus and Dill, 2006) and dugongs (Wirsing et al., 2007a) shift from using edge and interior microhabitats equally when sharks are absent to using edge microhabitats more often than interior ones despite higher tiger shark abundance in this microhabitat (Heithaus et al., 2006). This edge effect makes sense when the subcomponents of risk are considered. Edge microhabitats provide a greater probability of escape (to deep water) for dugongs and dolphins, which makes up for the greater encounter rate with predators (Heithaus and Dill, 2006; Wirsing et al., 2007a). Importantly, it is not confounded by microhabitat differences in food quantity and quality because fish and seagrass biomass do not vary across microhabitats, and seagrass quality is actually reduced along seagrass meadow edges (Heithaus and Dill, 2006; Wirsing et al., 2007a). Not all microhabitat variation appears to be important, however. For example, we have observed similar use of deep channels and open expanses of deep habitat relative to food supply by tiger sharks (Heithaus et al., 2006), dugongs (Wirsing et al., unpublished data), and dolphins (Heithaus and Dill, 2006).

Do small-scale shifts from interior to edge microhabitats result in strong broad-scale selection for seagrass patches with lots of edge when sharks are abundant? Though results from other species are pending, a new analysis involving dugongs suggests that the answer is yes. We compared the density of dugongs (individuals per $\mathrm{km}^{2}$ ) in four shallow seagrass patches (Fig. 1) during periods when tiger sharks were abundant (warm season, Sep-May in all years), present at low densities (three cold seasons, Jun-Aug), and largely absent (two cold seasons) (Heithaus, 2001; Wirsing et al., 2006; see Wirsing et al., 2007b, for transect methods) over 6 years (1997-1999, 2002-2004). We documented no selection for edge when sharks were absent or present in small numbers, and significant selection for patches offering the greatest proportion of edge microhabitat when sharks were prevalent (i.e., a significant edge* shark abundance interaction, Table 1, Fig. 2a; see Wirsing et al., 2007b, for transect methods). This pattern persisted after accounting for differences in food availability (seagrass biomass) among the 4 patches and annual variability in dugong numbers (Table 1). No such relationship was observed between seagrass patch area and dugong density; rather, because there was no relationship between bank area and the proportion of the bank that was edge habitat, dugongs selected for the smallest and second largest patches when sharks were most abundant (i.e., the interaction between area and shark abundance was non-significant, Table 1, Fig. 2b). 

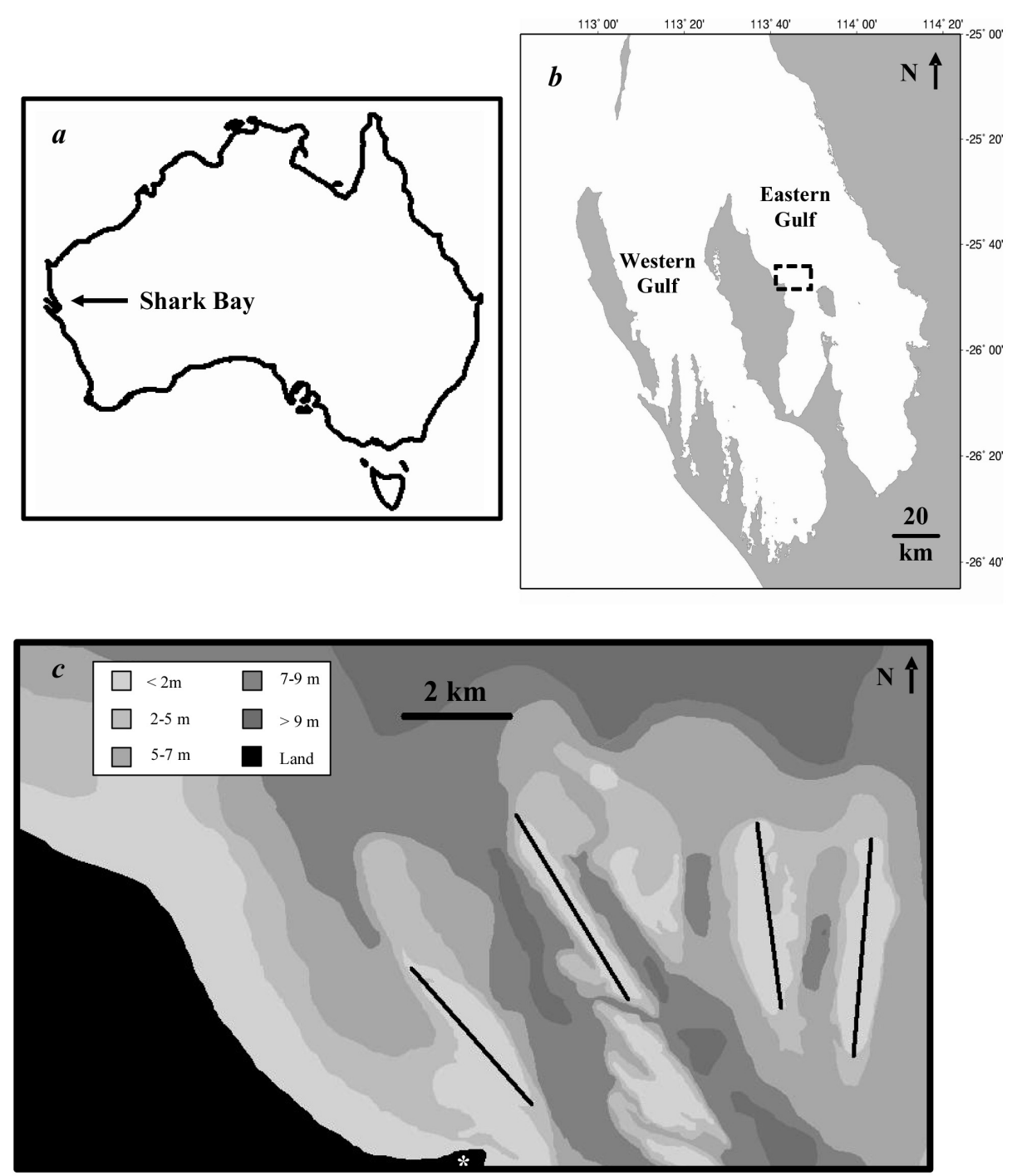

Fig. 1. Long-term studies have been conducted in Shark Bay, Western Australia, (a), offshore of Monkey Mia (dashed box, b). Survey zones (i.e., $400 \mathrm{~m}$ sighting belts; $n=14$ ) are stratified across shallow and deep habitats throughout the $160 \mathrm{~km}^{2}$ study area, (c; Monkey Mia denoted with a white asterisk at bottom). The four black lines indicate transect lines on banks used in analysis of dugong use of edges. Moving from east to west, the composition of these zones is $11.2 \%, 49.6 \%$, $42.7 \%$, and $13.8 \%$ edge. 
Table 1

General linear model of the influence of patch area $\left(\mathrm{km}^{2}\right)$, proportion of edge, food availability (seagrass biomass), tiger shark abundance (high, low, absent), year (1997-1999, 2002-2004), the interaction between area and shark abundance, and the interaction between edge and shark abundance on dugong density (no. per $\mathrm{km}^{2}$ ) over four shallow seagrass patches in Shark Bay, Western Australia. Significant relationships $(P=0.05)$ are highlighted in boldface

\begin{tabular}{lrrr}
\hline Term & \multicolumn{1}{c}{$\beta$} & \multicolumn{1}{c}{$t$-ratio } & \multicolumn{1}{c}{$P$} \\
\hline Area & -0.0059 & -0.62 & 0.535 \\
Edge & 0.0004 & 1.80 & 0.072 \\
Food & $<0.0001$ & 0.27 & 0.789 \\
Shark abundance & - & - & - \\
$\quad$ Absent & -0.0276 & -5.40 & $<\mathbf{0 . 0 0 1}$ \\
$\quad$ Low & 0.0031 & 0.74 & 0.460 \\
$\quad$ High & 0.0244 & 7.21 & $<\mathbf{0 . 0 0 1}$ \\
Year & 11.4602 & 5.38 & $<\mathbf{0 . 0 0 1}$ \\
Area*Shark abundance (Absent) & 0.0120 & 0.77 & 0.441 \\
Area*Shark abundance (Low) & -0.0020 & -0.16 & 0.873 \\
Area*Shark abundance (High) & -0.0090 & -0.86 & 0.391 \\
Edge*Shark abundance (Absent) & -0.0003 & -1.06 & 0.289 \\
Edge*Shark abundance (Low) & -0.0002 & -0.83 & 0.410 \\
Edge*Shark abundance (High) & 0.0005 & 2.41 & $\mathbf{0 . 0 1 6}$ \\
\hline
\end{tabular}

\section{WHAT DO THE SHARK BAY STUDIES CONTRIBUTE TO CONSERVATION?}

Collectively, the Shark Bay studies suggest that space use by marine vertebrates can be influenced not only by food availability in a patch and the overall density and distribution of predators but also by the configuration of the seascape and the structure of its constituent patches (i.e., patch layout and shape, microhabitat variation within each patch). There appears to be broader generality to this result; studies of rodents suggest that patch structure influences consumer behavior in terrestrial systems as well (Moenting and Morris, 2006; Ewers and Didham, 2007). For example, Moenting and Morris (2006) found that foraging patterns of meadow voles (Microtus pennsylvanicus) correlated with the amount of edge (circumference) rather than with the area characterizing artificially created patches in an abandoned hayfield. This result contradicted the widely held notion that relatively large patches in fragmented terrestrial environments should be protected because they are of the highest quality to consumers. By inference, then, efforts to designate critical habitat for vertebrates in coastal marine systems like Shark Bay will benefit from the consideration of each of these habitat characteristics, and those failing to do so may furnish incomplete or incorrect protective guidelines. Based upon our work, for example, critical habitat for dugongs in Shark Bay should include a matrix of deep channels and shallow seagrass patches with ample edge microhabitat, thereby allowing individual foragers to balance nutritional and anti-predator demands. In contrast, efforts to protect only large patches containing the most seagrass, which might derive from the prevailing notion that marine grazer population sizes are set by 

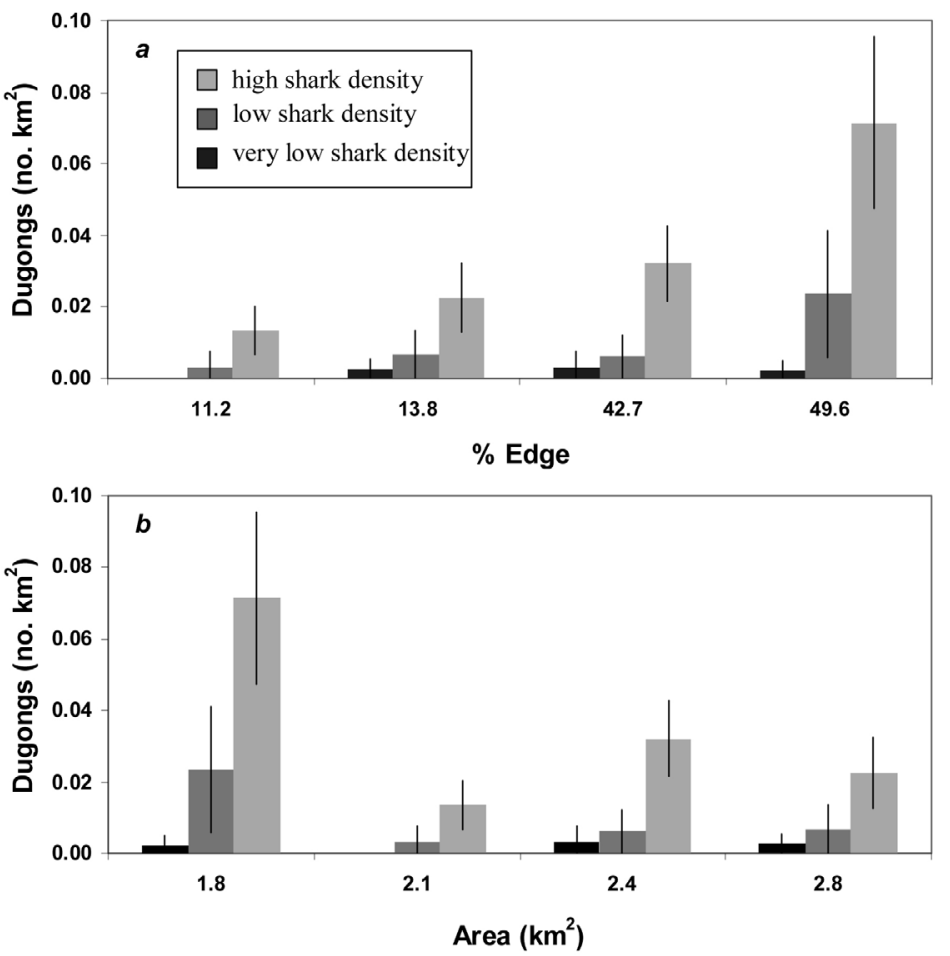

Fig. 2. Dugong density (no. per $\mathrm{km}^{2}$ ) in 4 seagrass patches in relation to microhabitat structure (\% edge coverage, (a), and total patch area $\left(\mathrm{km}^{2}\right)$, (b). Light gray bars represent use during the warm season (May-Sep), when tiger sharks were abundant; dark gray bars represent use during three cold seasons (Jun-Aug of 1999, 2003, and 2004) when sharks were present in low numbers; and black bars represent use during two cold seasons when sharks were essentially absent from the study area (1997 and 1998). Data were collected in Shark Bay, Western Australia. Years (19971999, 2002-2004) were pooled for the purposes of this figure because the effect of edge persisted after accounting for annual variability in dugong numbers. All density estimates are accompanied by $95 \%$ confidence intervals.

the gross biomass of seagrass available in a system (Jackson, 2001; Moran and Bjorndal, 2005), could easily leave dugongs with the choice between foraging under high risk of mortality or abandoning much of their food supply during periods when sharks abound. For a long-lived species with an interest in avoiding an early death and the need to ingest large quantities of low-quality food each day, both options would be costly.

Another lesson from our studies in Shark Bay is that predation risk is important in determining spatial distributions of many species and probably community dynamics (e.g., Heithaus et al., 2007b; Wirsing et al., 2007a,b). By extension, our work suggests that human disturbance that is perceived as predation risk (reviewed by Frid and Dill, 2002) could dramatically alter the suitability of microhabitats and the total area of high- 
quality habitat. For example, if we consider a hypothetical location where habitat selection decisions by large marine vertebrates are similar to those of grazers in Shark Bay and no predators and no disturbance are present (similar to Shark Bay when sharks are absent), shallow banks should be fully available and exploited. However, if disturbance were added, then large portions of the banks would go unused and the resources that were previously used would be reduced in availability. Theory predicts that if populations are limited to some extent by access to resources, such habitat shifts should lead to population declines (e.g., Walters and Juanes, 1993). Thus, managers should monitor habitat use relative to resources or animal densities across habitats prior to the onset of ecotourism or disturbances and use changes in habitat use as an indicator of possible negative impacts of disturbance. However, caution must be used in interpreting habitat use data when no overt changes in distribution are noted following the onset of disturbance. Individual animals with poor energetic state or body condition are less able to invest in anti-predator behavior or respond to human disturbance (Clark, 1994). Also, for habitat shifts to occur, disturbed animals must have somewhere adequate to escape to; otherwise lack of alternative habitats might preclude the option to abandon a site in response to disturbance or other perceived risks (Gill et al., 2001). Thus, in the absence of habitat shifts, it is nevertheless plausible that negative impacts of humans could manifest through reductions in body condition that could in turn lead to higher rates of starvation or predation (Anholt and Werner, 1995). In conclusion, habitat shifts can be a "red flag" for negative effects of human disturbance, but lack of such behavior should not be assumed to indicate a lack of effect without an analysis of individual condition and identification of alternative habitats.

A devil's advocate might argue that a priori analyses of habitat use are unnecessary for conservation because, as long as disturbance is minimized in important foraging areas, impacts on target species should be minimal. This view overlooks the possibility that, like predators, sources of anthropogenic disturbance might elicit prey responses remotely (i.e., from neighboring, unprotected areas). Our work in Shark Bay suggests that remote effects of predators may be common when certain habitats are perceived by prey to be intrinsically dangerous. For example, when present, tiger sharks elicit avoidance of risky interior portions of seagrass meadows by dugongs and green turtles (Wirsing et al.. 2007a; Heithaus et al., 2007b) even though they spend most of their time hunting along seagrass meadow edges. Studies of sirenians (manatees, Trichechus manatus, Nowacek et al., 2004; dugongs, A. Wirsing, unpublished data) suggest that boat disturbance can produce a similar effect. Specifically, these sirenians flee to deep water when disturbed, even when boats approach from deep habitats, suggesting that productive shallow feeding areas are perceived as intrinsically dangerous. Consequently, the restriction of boat disturbance to deep waters, where forage is less abundant, might nevertheless result in reduced use of critical foraging habitat in shallow waters and, ultimately, diminished population sizes (e.g., Walters and Juanes, 1993; Nelson et al., 2004). The lesson for marine conservation is that no-entry areas designed to reduce disturbance of critical habitats may not achieve desired results if these no-entry areas are perceived as intrinsically dangerous and commingle with areas where disturbance persists, meaning that a 
priori efforts to monitor habitat selection and identify habitats perceived by prey to be risky are crucial.

\section{OTHER POTENTIAL BEHAVIORAL INDICATORS IN MARINE SETTINGS}

While using habitat selection as a behavioral indicator for conservation would be useful in many coastal and some offshore habitats, it is more difficult to apply this framework to pelagic habitats where resources are less predictable and matches between predators and prey often do not occur at small spatial scales (e.g., Fauchald et al., 2000; Guinet et al., 2001). In such habitats, behavioral indicators based on the IFD or isodar analysis often may be impractical, except perhaps at large spatial scales that would be of little use for management (but see Gillis et al., 1993 and Blanchard et al., 2005, for applications of the IFD to fisheries). Thus, other behavioral indicators are needed to determine critical habitats or to identify changes in prey characteristics that should be of conservation concern.

Until recently, studies of large-bodied pelagic species (e.g., marine mammals, sea turtles, sea birds, sharks) have relied on ship-based surveys or catches on longlines to assess distribution patterns. However, the advent of satellite telemetry has allowed the collection of relatively fine-scale data on movements of individuals. Using these movement data, it is possible to determine areas where animals spend longer periods of time (i.e., move slower, "first-passage times") or make more turns ("area restricted searches"), which has been assumed to indicate foraging in areas of high food availability (e.g., Bailey and Thompson, 2006; Pinaud and Weimerskirch, 2007). Thus, changes in patch residence time and travel time between patches might serve as a behavioral indicator of changes in prey characteristics in pelagic systems and highlight areas of concern for managers. However, the possible use of such indicators requires further assessment, and in general foraging behavior must be used cautiously as an indicator of habitat quality (Parrish, 2005). For example, area-restricted searches identified by telemetry studies may not correlate well with prey capture rates (Robinson et al., 2007). Furthermore, current studies assume no effects of predators on movement patterns of large-bodied species, which may not be the case (see Wirsing et al., 2008). Our work in Shark Bay suggests that if prey availability and risk covary positively, areas of greatest search effort do not necessarily reflect the areas of highest food availability because habitat quality is not determined by food availability alone.

\section{SUMMARY}

One of the arguments leveled against the utility of behavior in guiding conservation practices is that behavioral biologists have contributed relatively little to real-world conservation efforts because, instead of conducting case-by-case studies, they make relatively hypothetical suggestions (Caro, 2007). While this may be true for some aspects of behavioral ecology, where decisions may vary substantially within and among species, such is not the case for habitat selection in the context of trade-offs between 
food and predation risk. Indeed, one striking feature of the behavior of species under risk of tiger shark predation in Shark Bay is the similarity between the decision rules by which they are governed and those for vastly different taxa, including grasshoppers threatened by spiders (e.g., Schmitz, 2006) and elk threatened by wolves (e.g., Ripple and Beschta, 2005). Thus, behavioral ecology can provide a strong, unifying framework for identifying critical habitats and signaling anthropogenic changes to the environment. Most importantly, as highlighted a decade ago by Sutherland (1998), habitat selection theory can be used to generate reliable predictions about how environmental changes or anthropogenic disturbance will affect species in novel environments and before potentially deleterious activities are undertaken. For example, predictions of desirable community-level responses to the reintroduction of wolves to Yellowstone National Park, USA that were based on habitat selection theory have recently been validated (Ripple and Beschta, 2007). Marine conservation efforts will be enhanced by making similar use of this body of theory both to furnish indicators of anthropogenic effects and to predict the consequences of human activities.

\section{ACKNOWLEDGMENTS}

We would like to thank Burt Kotler, Joel Brown, and Doug Morris for inviting us to contribute to this volume. We thank the many volunteers who have aided us with fieldwork over the years. Our research in Shark Bay has been supported by NSERC Canada (A6869), the National Science Foundation (OCE0526065), PADI Foundation, and National Geographic's Expeditions Council. This paper is contribution number 33 of the Shark Bay Ecosystem Research Project.

\section{REFERENCES}

Altendorf, K.B., Laundre, J.W., Gonzalez, C.A.L., Brown, J.S. 2001. Assessing effects of predation risk on foraging behavior of mule deer. J. Mammal. 82: 430-439.

Anholt, B.R., Werner, E.E. 1995. Interaction between food availability and predation mortality mediated by adaptive behavior. Ecology 76: 2230-2234.

Bailey, H., Thompson, P. 2006. Quantitative analysis of bottlenose dolphin movement patterns and their relationship with foraging. J. Anim. Ecol. 75: 456-465.

Bejder, L., Whitehead, H., Samuels, A., Mann, J., Connor, R., Gales, N., Heithaus, M., Watson-Capps, J., Flaherty C., Krutzen, M. 2006. Detrimental effects of cumulative, long-term exposure to vessel activity on habitat use of Indo-Pacific bottlenose dolphins. Conserv. Biol. 20: 1791-1798.

Blanchard, J.L., Mills, C., Jennings, S., Fox, C.J., Rackham, B.D., Eastwood, P.D., O’Brien, C.M. 2005. Distribution-abundance relationships for North Sea Atlantic cod (Gadys morhua): observation versus theory. Can. J. Fish. Aquat. Sci. 62: 2001-2009.

Brown, J.S., Kotler, B.P. 2004. Hazardous duty pay and the foraging cost of predation. Ecol. Lett. 7: 999-1014.

Buchholz, R. 2007. Behavioral biology: an effective and relevant conservation tool. Trends Ecol. Evol. 22: 401-407. 
Caro, T.M. 2005. Behavioural indicators of exploitation. Ethol. Ecol. Evol. 17: 189-194.

Caro, T.M. 2007. Behavior and conservation: a bridge too far? Trends Ecol. Evol. 22: 394-400.

Clark, C.W. 1994. Antipredator behavior and the asset-protection principle. Behav. Ecol. 5: $159-170$.

Crowder, L.B. 2005. Back to the future in marine conservation. In: Norse, E.A., Crowder, L.B., eds. Marine Conservation Biology. Island Press, Washington, DC, pp. 19-29.

Dill, L.M., Heithaus, M.R., Walters, C.J. 2003. Behaviorally-mediated indirect species interactions in marine ecosystems and their importance to conservation and management. Ecology 84:1151-1157.

Ewers, R.M., Didham, R.K. 2007. The effect of fragment shape and species' sensitivity to habitat edges on animal population size. Conserv. Biol. 21: 926-936.

Fauchald, P.K., Erikstad, E., Skarsfjord, H. 2000. Scale-dependent predator-prey interactions: the hierarchical spatial distribution of seabirds and prey. Ecology 81: 773-783.

Fretwell, S.D., Lucas, H.L. 1969. On territorial behavior and other factors influencing habitat distribution in birds. Acta Biotheor. 19: 16-36.

Frid A., Dill, L.M.. 2002. Human-caused disturbance stimuli as a form of predation risk. Conserv. Ecol. 6: http://www.consecol.org/Journal/vol6/iss1/art11/print.pdf

Gales, N., McCauley, R.D., Lanyon, J., Holley, D. 2004. Change in abundance of dugongs in Shark Bay, Ningaloo and Exmouth Gulf, Western Australia: evidence for large-scale migration. Wildl. Res. 31: 283-290.

Gill, J.A., Norris, K., Sutherland, W.J. 2001. Why behavioural responses may not reflect the population consequences of human disturbance. Biol. Conserv. 97: 265-268.

Gill, J.A., Sutherland, W.J., Watinson, A.R. 1996. A method to quantify the effects of human disturbance on animal populations. J. Appl. Ecol. 33: 786-792.

Gillis, D.M., Peterman, R.M., Tyler, A.V. 1993. Movement dynamics in a fishery: application of the ideal free distribution to spatial allocation of effort. Can. J. Fish. Aquat. Sci. 50: 323-333.

Gilroy, J.J., Sutherland, W.J. 2007. Beyond ecological traps: perceptual errors and undervalued resources. Trends Ecol. Evol. 22: 351-356.

Griffin, C.A.M., Thaler, J.S. 2006. Insect predators affect plant resistance via density- and traitmediated indirect interactions. Ecol. Lett. 9: 338-346.

Guinet, C., Dubroca, L., Lea, M.A., Goldsworthy, S., Cherel, Y., Duhamel, G., Bonadonna, F., Donnay, J.P. 2001. Spatial distribution of foraging female Antarctic fur seals Arctocephalus gazelle in relation to oceanographic variables: a scale-dependent approach using geographic information systems. Mar. Ecol. Prog. Ser. 264: 251-264.

Halpern, B.S., Selkoe, K.A., Micheli, F., Kappel, C.V. 2007. Evaluating and ranking the vulnerability of global marine ecosystems to anthropogenic threats. Conserv. Biol. 21: 1301-1315.

Heithaus, M.R. 2001. The biology of tiger sharks, Galeocerdo cuvier, in Shark Bay, Western Australia: sex ratio, size distribution, diet and seasonal changes in catch rates. Environ. Biol. Fish. 61: 25-36.

Heithaus, M.R. 2005. Habitat use and group size of pied cormorants (Phalacrocorax varius) in a seagrass ecosystem: possible effects of food abundance and predation risk. Mar. Biol. 147: 27-35.

Heithaus, M.R., Dill, L.M. 2002. Food availability and tiger shark predation risk influence bottlenose dolphin habitat use. Ecology 83: 480-491.

Heithaus, M.R., Dill, L.M. 2006. Does tiger shark predation risk influence foraging habitat use by bottlenose dolphins at multiple spatial scales? Oikos 114:257-264.

Heithaus, M.R., Frid, A., Wirsing, A.J., Bejder, L., Dill, L.M. 2005. The biology of green and 
loggerhead turtles under risk from tiger sharks at a foraging ground. Mar. Ecol. Prog. Ser. 288: 285-294.

Heithaus, M.R., Hamilton, I.M., Wirsing, A.J., Dill, L.M. 2006. Validation of a randomization procedure to assess animal habitat preferences: microhabitat use of tiger sharks in a seagrass ecosystem. J. Anim. Ecol. 75: 666-676.

Heithaus, M.R., Burkholder, D., Hueter, R.E., Heithaus, L.I., Pratt, H.W. Jr, Carrier, J.C. 2007a. Spatial and temporal variation in shark communities of the lower Florida Keys and evidence for historical population declines. Can. J. Fish. Aquat. Sci. 64: 1302-1313.

Heithaus, M.R., Frid, A., Wirsing, A.J., Dill, L.M., Fourqurean, J., Burkholder, D., Thomson, J., Bejder, L. 2007b. State-dependent risk-taking by green sea turtles mediates top-down effects of tiger shark intimidation in a marine ecosystem. J. Anim. Ecol. 76: 837-844.

Hochman, V., Kotler, B.P. 2007. Patch use, apprehension, and vigilance behavior of Nubian Ibex under perceived risk of predation. Behav. Ecol. 18: 368-374.

Jackson, J.B.C. 2001. What was natural in the coastal oceans? Proc. Nat. Acad. Sci. USA 98: 5411-5418.

Jackson, J.B.C., Kirby, M.H., Berger, W.H., Bjorndal, K.A., Botsford, L.W., Borque, B.J., Bradbury, R.H., Cooke, R., Erlandson, J., Estes, J.A., Hughes, T.P., Kidwell, S., Lange, C.B., Lenihan, H.S., Pandolfi, J.M., Peterson, C.H., Steneck, R.S., Tegner, M.J., Warner, R.R. 2001. Historical overfishing and the recent collapse of coastal ecosystems. Science 146: 629-638.

Knight, T.W., Morris, D.W. 1996. How many habitats do landscapes contain? Ecology 77: 1756-1764.

Kotler, B.P., Brown, J.S., Bouskila, A. 2004. Apprehension and time allocation in gerbils: the effects of predatory risk and energetic state. Ecology 85: 917-922.

Laundré, J.W., Hernández, L., Altendorf, K.B. 2001. Wolves, elk, and bison: reestablishing the "landscape of fear" in Yellowstone National Park, USA. Can. J. Zool. 79: 1401-1409.

Lotze, H.K., Lenihan, H.S., Bourque, B.J., Bradbury, R.H., Cooke, R.G., Kay, M.C., Kidwell, S.M., Kirby, M.X., Peterson, C.H., Jackson, J.B. 2006. Depletion, degredation, and recovery potential of estuaries and coastal seas. Science 312: 1806-1809.

Lusseau, D. 2004. The hidden cost of tourism: detecting long-term effects of tourism using behavioral information. Ecol. Soc. 9: http://www.ecologyandsociety.org/vol9/iss1/art2/

Moenting, A.E., Morris, D.W. 2006. Disturbance and habitat use: is edge more important than area? Oikos 115: 23-32.

Moran, K.L., Bjorndal, K.A. 2005. Simulated green turtle grazing affects structure and productivity of seagrass pastures. Mar. Ecol. Prog. Ser. 305: 235-247.

Morris, D.W. 2003a. How can we apply theories of habitat selection to wildlife conservation and management? Wildl. Res. 30: 303-319.

Morris, D. 2003b. Towards an ecological synthesis: a case for habitat selection. Oecologia 136: $1-13$.

Myers, R.A., Baum, J.K., Shepherd, T.D., Powers, S.P., Peterson, C.H. 2007. Cascading effects of the loss of apex predatory sharks from a coastal ocean. Science 315: 1846-1850.

Nelson, E.H., Matthews, C.E., Rosenheim, J.A. 2004. Predators reduce prey population growth by inducing changes in prey behaviour. Ecology 85: 1853-1858.

Norse, E.A., Crowder, L.B. 2005. Marine conservation biology: the science of maintaining the sea's biodiversity. Island Press, Washington, DC.

Nowacek, S.M., Wells, R.S., Owen, E.C.G., Speakman, T.R., Flamm, R.O., Nowacek, D.P. 2004. Florida manatees, Trichechus manatus latirostris, respond to approaching vessels. Biol. Conserv. 119: 517-523. 
Orth, R.J., Carruthers, T.J.B., Dennison, W.C., Duarte, C.M., Fourqurean, J.W., Heck, K.L.Jr., Hughes, R., Kendrick, G.A., Kenworthy, W.J., Olyarnik, S., Short, F.T., Waycott, M., Williams, S.L. 2006. A global crisis for seagrass ecosystems. BioScience 56: 987-996.

Papastamatiou, Y. P., Wetherbee, B.M., Lowe, C.G., Crow, G.L. 2006. Distribution and diet of four species of carcharhinid shark in the Hawaiian Islands: evidence for resource partitioning and competitive exclusion. Mar. Ecol. Prog. Ser. 320: 239-251.

Parrish, J.K. 2005. Behavioral approaches to marine conservation. In: Norse, E.A., Crowder, L., eds. Marine Conservation Biology. Island Press, Washington, DC, pp. 80-104.

Peacor, S.D., Werner, E.E. 2001. The contribution of trait-mediated indirect effects to the net effects of a predator. Proc. Nat. Acad. Sci. USA 98: 3904-3908.

Pinaud, D., Weimerskirch, H. 2007. At-sea distribution and scale-dependent foraging behavior of petrels and albatrosses: a comparative study. J. Anim. Ecol.76: 9-19.

Preen, A.R., Marsh, H., Lawler, I.R., Prince, R.I.T., Shepherd, R. 1997. Distribution and abundance of dugongs, turtles, dolphins, and other megafauna in Shark Bay, Ningaloo Reef and Exmouth Gulf, Western Australia. Wildl. Res. 24: 185-208.

Preisser, E.L., Bolnick, D.I., Benard, M.F. 2005. Scared to death? The effects of intimidation and consumption in predator-prey interactions. Ecology 86: 501-509.

Reynolds, J.D., Jennings, S. 2000. The role of animal behavour in mrine conservation. In: Gosling, L.M., Sutherland, W.J., eds. Behaviour and conservation. Cambridge University Press, Cambridge, pp. 238-257.

Ripple, W.J., Beschta, R.L. 2003. Wolf reintroduction, predation risk, and cottonwood recovery in Yellowstone National Park. For. Ecol. Manag. 184: 299-313.

Ripple, W.J., Beschta, R.L.2005. Wolves and the ecology of fear: Can predation risk structure ecosystems? Bioscience 54: 755-766.

Ripple, W. J., Beschta, R.L. 2007. Restoring Yellowstone's aspen with wolves. Biol. Conserv. 138: 514-519.

Ripple, W.J., Larsen, E.J., Renkin, R.A., Smith, D.W. 2001. Trophic cascades among wolves, elk and aspen on Yellowstone National Park's northern range. Biol. Conserv. 102: 227-234.

Robinson, P.W., Tremblay, Y., Crocker, D.E., Kappes, M.A., Kuhn, C.E., Shaffer, S.A., Simmons, S.E., Costa, D.P. 2007. A comparison of indirect measures of feeding behavior based on ARGOS tracking data. Deep-sea Res. Part II-Topical Stud. Oceanogr. 54: 356-368.

Schmitz, O.J. 2006. Scaling from plot experiments to landscapes: studying grasshoppers to inform forest ecosystem management. Oecologia 145: 225-234.

Schmitz, O.J., Hamback, P.A., Beckerman, A.P. 2000. Trophic cascades in terrestrial systems: a review of the effects of carnivore removals on plants. Am. Nat. 155: 141-153.

Sutherland, W.J. 1998. The importance of behavioural studies in conservation biology. Anim. Behav. 56: 801-809.

Tregenza, T. 1995. Building on the ideal free distribution. Adv. Ecol. Res. 26: 253-307.

Trussel, G.C., Ewanchuk, P.J., Matassa, C.M. 2006. Habitat effects on the relative importance of trait- and density-mediated indirect interactions. Ecol. Lett. 9: 1245-1252.

van Baalen, M., Sabelis, M.W. 1993. Coevolution of patch selection strategies of predators and prey and the consequences for ecological stability. Am. Nat. 142: 646-670.

Walters, C., Juanes, F. 1993. Recruitment limitation as a consequence of natural selection for use of restricted feeding habitats and predation risk taking by juvenile fishes. Can. J. Fish. Aquat. Sci. 50: 2058-2070.

Williams, R., Lusseau, D., Hammond, P.S. 2006. Estimating relative energetic costs of human disturbance to killer whales (Orcinus orca). Biol. Conserv. 133: 301-311. 
Wirsing, A.J., Heithaus, M.R., Dill, L.M. 2006. Tiger shark (Galeocerdo cuvier) abundance and growth rates in a subtropical embayment: evidence from seven years of standardized fishing effort. Mar. Biol. 4: 961-968.

Wirsing, A.J., Heithaus, M.R., Dill, L.M. 2007a. Living on the edge: dugongs prefer foraging microhabitats that allow escape rather than avoidance of predators. Anim. Behav. 74: 93-101.

Wirsing, A.J., Heithaus, M.R., Dill, L.M. 2007b. Fear factor: Do dugongs (Dugong dugon) trade food for safety from tiger sharks (Galeocerdo cuvier)? Oecologia 153: 1031-1040.

Wirsing, A.J., Heithaus, M.R., Frid, A., Dill, L.M. 2008. Seascapes of fear: evaluating sublethal predator effects experienced and generated by marine mammals. Mar. Mamm. Sci. 24: 1-15.

Yunger, J.A., Meserve, P.L, Gutierrez, J.R. 2002. Small-mammal foraging behavior: mechanisms for coexistence and implication for population dynamics. Ecol. Monog. 72: 561-577. 